\title{
Distributive/integrative negotiation strategies in cross-cultural contexts: a comparative study of the USA and Italy
}

\author{
Sara Benetti ${ }^{1}$, Enrique Ogliastri ${ }^{1,2}$ and Andrea Caputo ${ }^{3,4}$ (D) \\ ${ }^{1}$ INCAE Business School, P.O. Box 960-4050, Alajuela, Costa Rica, ${ }^{2}$ IE University Business School, Serrano 105, Madrid \\ 28006, Spain, ${ }^{3}$ Department of Economics \& Management, University of Trento, Via Virgilio Inama 4, 38122, Trento, Italy \\ and ${ }^{4}$ Lincoln International Business School, University of Lincoln, Brayford Pool, LN6 7TS Lincoln, UK \\ Author for correspondence: Andrea Caputo, E-mail: andrea.caputo@unitn.it
}

(Received 7 September 2020; revised 15 December 2020; accepted 22 December 2020; first published online 1 February 2021)

\begin{abstract}
Integrative and distributive negotiation strategies are a key paradigm of practice, teaching, and research. Are these US-formulated negotiation prototypes valid in the rest of the world? Adopting a cross-cultural view, we analyze a sample of 214 foreigners who detailed the negotiation behavior they faced in Italy (134) and in the United States (80). Implementing latent class analysis, we identify three clusters of negotiation prototypes. Our findings show how the Country is a predictor for cluster membership, and peculiar cultural traits of the two groups contribute to explain the differences in negotiation strategies. Three prototypes emerged: a typically distributive, an emotional integrative (mostly Italian), and an impersonal integrative (mostly American). Results show how the handling of emotions is a crucial part of the interaction for Italian negotiators, regardless of their orientation toward negotiation strategies, implying a cultural influence toward handling emotions in negotiations.
\end{abstract}

Key words: Culture; integrative negotiations; Italy; latent class analysis; negotiation prototypes; USA

\section{Introduction}

The ability to negotiate internationally and across cultures has become vital for businesses (Caputo, Ayoko, Amoo, \& Menke, 2019a; Ogliastri \& Quintanilla, 2016). However, cross-cultural negotiation entails communication difficulties and challenges (Imai \& Gelfand, 2010; Liu, Chua, \& Stahl, 2010; Ramirez Marin, Olekalns, \& Adair, 2019), and seems to result in lower outcomes (e.g., Brett, Gunia, \& Teucher, 2017). The behavioral theory of negotiations (Walton \& McKersie, 1965), which is the most widespread theoretical framework in negotiation (Cutcher-Gershenfeld \& Kochan, 2015), posits how fundamental to negotiation success is the choice between a distributive (or positional) and an integrative (or principled) negotiation strategy (Patton, 2015). These two prototypes were originally developed in the United States and have been extensively assumed to hold their importance universally (Gelfand \& Brett, 2004). Cross-cultural studies in negotiation have been flourishing during the last few decades, especially research focusing on the effects of social, political, and cultural contexts on the negotiation process, strategies, and outcomes. Yet, most research on intercultural negotiations continues to tend to compare distant cultures, such as eastern versus western (e.g., Adler \& Graham, 2017; Zhang, Oetzel, Ting-Toomey, \& Zhang, 2019), whereas a minority analyzes cross-cultural interactions among similar ones, such as westerners.

(c) Cambridge University Press and Australian and New Zealand Academy of Management 2021. This is an Open Access article, distributed under the terms of the Creative Commons Attribution licence (http://creativecommons.org/licenses/by/4.0/), which permits unrestricted re-use, distribution, and reproduction in any medium, provided the original work is properly cited. 
In contrast, we ask to what extent the prototypes of integrative and distributive negotiators usefully represent intercultural negotiation behavior in two western cultures, the USA and Italy. Italy, in particular, has been largely neglected in studies of cross-cultural negotiation despite its economic importance. Consequently, this study aims to contribute to fill a gap in the literature by answering the following research questions: are the behavioral theory of negotiations' prototypes (distributivepositional vs. integrative-principles), developed in the United States, generalizable to other western cultures of the world? And, what are the patterns of negotiation in Italy and the perception of foreigners who live and work there? By answering these questions, we would be contributing to the call by Brett, Gunia, and Teucher (2017) for more investigation of anomalies in extant research that could be explained by studying the cultural relevance of negotiation theory and consideration of new constructs for a truly global understanding of negotiations.

Our study focuses on behaviors that people from different national cultures demonstrate during negotiation processes, as reported by counterparts who have been negotiating with them. We use a sample of 214 reports on American and Italian negotiators to identify clusters of negotiation prototypes. Employing latent class analysis (LCA) (Collins \& Lanza, 2010), we aim to determine whether belonging to a specific country culture affects the probability of belonging to one of the negotiator clusters. To study the cultural relevance of the behavioral theory of negotiations (Walton \& McKersie, 1965), we use eight questions directly related to the principles of negotiation suggested by Fisher, Ury, and Patton (1981). They propose a framework to help achieving a 'good agreement' and avoid getting stuck in a positional bargaining. In particular, they highlight that integrative agreements are the result of four negotiation principles. First of all, negotiators should separate the people from the issue to maintain the relationship, by understanding the other parties' interpretations and perceptions, an adequate handling of emotions, and effective communication and active listening. Second, the negotiating parties should focus on interests at stake, rather than their positions. Third, it is fundamental to generate creative options to solve the problem, from an inventive and unconstrained brainstorming initial process to a clear evaluation and refinement of promising proposals to negotiate on. Finally, the authors suggest agreeing upon and using objective criteria to resolve differences during the negotiation process. The framework and principles proposed by Fisher, Ury, and Patton (1981) are extremely popular and still extensively used by both practitioners and scholars, and linked to the distributive/integrative models (Patton, 2015); therefore, we apply our variable selection based on this theoretical construct.

The analysis leads to the identification of three negotiation prototypes and country culture is a significant predictor of clusters' membership. Most North American negotiators adopt an integrative strategy, using objectivity, technical criteria, and avoiding haggling, even though they are impersonal and less oriented to explore the interests of the counterpart ('impersonal integrative'). Italian negotiators are fairly equally spread between a distributive and an integrative negotiation prototype. The distributive one is the classical type, who conceives the negotiation as a zero-sum game and undertakes a bargaining process. The other one shows some of the typical traits of the integrative negotiation strategy, being oriented to explore interests and to create mutual value within a colleagueship process but is also expressing and dealing with emotions during the negotiation, a controversial subject of research and practice. This original 'emotional integrative' prototype of negotiators that we find for Italy represents one of the most interesting contribution of implementing an LCA in this context.

\section{Theoretical background}

\section{Integrative versus distributive negotiations}

Negotiations occur in situations where two or more parties with conflicting interests jointly seek a mutual agreement to reconcile their differences, rather than resorting to force or trial (e.g., Lax \& 
Sebenius, 1986). Over the years, as scholars have built a broad body of theoretical and empirical literature on negotiation - which embraces the development and validation of models and techniques for making agreements - they have defined two predominant negotiation prototypes: distributive and integrative negotiation model strategies (Cutcher-Gershenfeld \& Kochan, 2015; Fisher, Ury, \& Patton, 1981; Patton, 2015; Walton \& McKersie, 1965).

The distributive (or positional) negotiation strategy treats the negotiation process as positional bargaining, in which each party tries to maximize its share of payoffs, which are perceived as a fixed sum (Patton, 2015; Pruitt \& Rubin, 1986). Accordingly, negotiators assume they must distribute a fixed value, so one party will lose and the other will win (the so-called win-lose, zero-sum, or fixed-pie configuration). This focus on distributing value implies inefficiencies, distorts the negotiation relationship, and complicates creating value in the negotiation (Brett \& Thompson, 2016).

In the integrative (or principled) negotiation strategy, parties explore options to increase the size of the joint gain, before focusing on the division of payoffs (Patton, 2015; Pruitt \& Rubin, 1986). This tends to solve problems jointly and to benefit all parties, as negotiators distribute the increased value by applying objective criteria (rather than haggling, as in distributive negotiation) (Fisher et al., 1981). Integrative negotiation is claimed to be superior to distributive negotiation because it gradually yields a more efficient and longer term agreement, to the benefit of all parties (Brett \& Thompson, 2016).

\section{Negotiation in cross-cultural contexts}

The behavioral theory of negotiations was initially developed in the context of North American labor negotiations and business agreements (Walton \& McKersie, 1965), and since then a vast research effort has been stimulated to expand the understanding of international negotiations involving individuals from different cultures. The main, common question that has been driving this research stream is whether distributive versus integrative behaviors in cross-cultural negotiations differ in important ways from those in intracultural negotiations (Adair \& Brett, 2005).

Although the theoretical models seem generally valid across cultures (Graham, Mintu, \& Rodgers, 1994), numerous studies confirm that there are some substantial differences among cultural groups (Caputo, Marzi, Maley, \& Silic, 2019b; Ma, Lee, \& Yu, 2008). Culture profoundly affects how people think, communicate, and behave, including the types of agreements they make and the way they reach them (Brett, 2007, 2017; Salacuse, 1999). A particularly prolific stream of research has compared negotiation processes exhibited by individuals from different countries, mainly using the United States as a benchmark and trying to explain any substantial deviation from the reference models in terms of different cultural qualities and idiosyncrasies (e.g., Adair \& Brett, 2005; Adair, Okumura, \& Brett, 2001; Cai \& Fink, 2002; Gunia, Brett, \& Gelfand, 2016; Morris \& Gelfand, 2004).

Most of these studies have used Hofstede's (2011) five-dimensional model of national cultures, the dimensions being power distance, uncertainty avoidance, individualism/collectivism, masculinity/femininity, and long-/short-term orientation (Adair \& Brett, 2005; Adair, Hideg, \& Spence, 2013; Kirkman, Lowe, \& Gibson, 2006; Vieregge \& Quick, 2011). For example, individualistic cultures may be expected to be more self-centered and focused on personal gains (Brett \& Okumura, 1998), whereas negotiators from a collectivist culture concentrate more on forming a relationship and discriminate between in-group and out-group partners, feeling strongly linked to the former and promoting their collective interests and goals during the negotiation process, an approach that can lead to higher joint profits (Cai, Wilson, \& Drake, 2000). Caputo and colleagues (2018, 2019a) found that power distance and masculinity increase the preference for a distributive strategy, whereas uncertainty avoidance and collectivism increase the preference for an integrative one.

However, some scholars argue that Hofstede's original sample fails to capture how culture evolved over time and neglects within-country cultural differences (e.g., Kirkman, Lowe, \& 
Gibson, 2006). The Globe study (House, Hanges, Javidan, Dorfman, \& Gupta, 2004) adds cultural dimensions and points to differences between culture 'as it is now' and 'as it should be.' Hall (1976) identifies two important cultural characteristics: monochronic/polychronic time and communication context. Polychronicity is necessary to create value by package negotiations rather than issue by issue. The implicit communication context can be high or low. Negotiators from low-context communication cultures favor direct information sharing, whereas those from highcontext communication cultures assume that some meanings and nuances must be inferred (Adair et al., 2004).

A recent stream of research focuses on the distinction among dignity, honor, and face cultures (Aslani et al., 2016; Brett \& Thompson, 2016; Leung \& Cohen, 2011). Other studies have highlighted other aspects that can impact the outcomes of negotiation, including emotions (Gelfand \& Brett, 2004; Ogliastri \& Quintanilla, 2016; Schlegel, Mehu, van Peer, \& Scherer, 2018), consensus building and trust (Brett, Gunia, \& Teucher, 2017; Liu, Friedman, Barry, Gelfand, \& Zhang, 2012; Yao, Zhang, \& Brett, 2017), cognitive biases (Caputo, 2013, 2016; Morris \& Gelfand, 2004), and cultural intelligence (Caputo, Ayoko, \& Amoo, 2018; Caputo et al., 2019a; Groves, Feyerherm, \& Gu, 2015; Imai \& Gelfand, 2010).

Cultural differences among international negotiators can represent a serious obstacle to effective negotiation (Adler \& Aycan, 2018; Graham, Mintu, \& Rodgers, 1994; Salacuse, 1999), as they potentially affect the role of the negotiators, the nature of communication, mutual perceptions, preferences, and the negotiation style itself, finally determining the outcome and form of the agreement (Cai, Wilson, \& Drake, 2000; Gelfand \& Brett, 2004; Gelfand, Brett, Gunia, Imai, Huang, \& Hsu, 2013; Usunier, 2018). Nevertheless, negotiators from different cultures will not always clash and reach suboptimal agreements; indeed, differences may offer opportunities. Adler (1980), who refers to this as the 'culturally synergistic' approach, claims that international negotiators can generate mutually beneficial options by identifying interests that different parties value differently. In other words, in cross-cultural negotiations, the process complexity increases, but the opportunities of reaching an agreement with joint gains also improve when negotiators recognize their fundamental compatibilities instead of focusing on stereotypes.

In sum, there is still a need to clarify how distinctive cultural traits affect negotiation processes and outcomes: to move from qualitative descriptions and manuals of 'dos and don'ts' toward a more comprehensive and profound examination of the influence of culture on negotiators' tactics, outcomes, motives, and cognitions, along with a deeper understanding of the broad effects of intercultural interaction (Adler \& Aycan, 2018). To this end, we formulate two main propositions for research:

Proposition 1: The integrative and distributive negotiation prototypes should be valid in both Italy and the USA.

Proposition 2: The negotiation prototypes in Italy and the USA should differ.

We aim to determine whether the distributive and integrative negotiator prototypes can be validated within two distinct Western cultural clusters: the Latin European and the Anglo (see, e.g., House et al., 2004). Indeed, the characterization of Italy and the United States along the cultural dimensions proposed by Hofstede (2001) suggests that although they share some cultural traits (e.g., they are both classified in middle-to-low positions for power distance and relatively high for masculinity), the North American country exhibits the highest position on individualism and Italy presents stronger traits in terms of uncertainty avoidance and long-term orientation. ${ }^{1}$ These divergencies can have a significant effect on negotiation strategies. With our analysis, we

\footnotetext{
${ }^{1}$ Appendix 1 reports the Hofstede's cultural indices for Italy and the United States (https://geerthofstede.com/researchand-vsm/dimension-data-matrix/).
} 
also contribute to the study of Italy, a major world economic player, ${ }^{2}$ which is rarely mentioned in studies on cross-cultural negotiations.

\section{Methods}

\section{Research design and data collection}

We sought a method that would allow us to investigate real negotiations and isolate focal constructs, and would not be influenced by previous respondent behaviors (Caputo, 2016; Ogliastri \& Quintanilla, 2016). We therefore adopted a mixed methods approach (Hesse-Biber, 2010), triangulating the results of LCA (Collins \& Lanza, 2010) with the testimonies about experiences of direct negotiations in different business contexts (Ogliastri \& Quintanilla, 2016).

We adopted a previously validated questionnaire made of 20 open-ended questions ${ }^{3}$ (see, for further explanation, Ogliastri \& Quintanilla, 2016). The answers were coded into 53 categorical variables in order to make the data easily intelligible in mostly Yes/No/Don't know answers. An example of the codebook is presented in Appendix 3. This is a quantitative data set, with face validity and conveniently structured for statistical analysis. We gathered the data within the framework of theory of practice (Bourdieu, 1977), using experiences to develop theory (Broome, 2017) and integrating teaching, practice, theory, and research (Ebner \& Parlamis, 2017). To reduce the risk that results might be biased by specific contextual events, data were collected between 2010 and 2018. Our database consists of thorough records of intercultural negotiation experiences and includes 214 observations, from foreign experienced managers, about American $(N=80)$ and about Italian $(N=134)$ negotiators.

Lewicki, Saunders, and Barry (2020) report how one of the main limitations of the vast body of research in negotiation consist of result being drawn from laboratory experimental design rather than accounts of real negotiations. Therefore, answering to this call for a closer to reality approach in negotiation research, we employed a convenience sampling technique gathering data from interviews with experienced managers. The interviews were carried out by international students in an MBA negotiation course as part of their assignment. To avoid the risks associated with selfreported measures, each $\mathrm{MBA}$ student conducted an interview with a foreign manager (i.e., expat), who reported the most common or normal behavior of his counterparts in the country of origin of the student. By applying this method we reduced the interviewer biases present in normal qualitative research, as a different interviewer was employed for each interviewee. In addition, we limited the research bias as we, the researchers, were not directly involved in the interview, therefore separating the cognitive processes of data collection, interpretation, and analysis. Moreover, our method guaranteed that the accounts were provided by counterparts not sharing the same cultural background, ensuring a better report of cross-cultural interactions. That meant that the managers that explained their negotiation experiences in Italy (or in the USA) were from different backgrounds and nationalities, helping to further reduce possible biased interpretations of results.

We then developed a codebook, comprising 53 variables, to convert the qualitative information from the interviews into quantitative data. ${ }^{4}$ To further limit the researcher bias, five graduate research assistants were employed over 5 years with the task to code interviews, with an interrater reliability coefficient (Fleiss' kappa) of .65, implying 'substantial agreement' in the coding phase.

\footnotetext{
${ }^{2}$ For example, the Financial Times reported on March 22, 2016 that the value of cross-border merger and acquisition deals in Italy reached a new high in 2015 at over \$50bn; Italian companies were the most targeted by foreign acquisitions in the European Union after the UK, along with French ones (https://www.ft.com/content/df73311e-0b35-3d5c-aaf9-e12e49f6eee3). Caputo $(2012,2019)$ thoroughly analyzed the negotiation process of the Fiat-Chrysler deal, one of the most relevant negotiations led by an Italian firm in the last decade.

${ }^{3}$ Appendix 2 reports the 20 questions of the survey.

${ }^{4}$ Appendix 3 reports a sample of the codebook used to convert the information collected during the interviews into the categorical variables of our quantitative database.
} 
In addition, as a preliminary analysis showed interesting results about the Italian negotiators that begged further analysis due to the lack of research about Italian negotiators, we complemented the study with 86 qualitative interviews based on a different questionnaire ${ }^{5}$ and focusing on the specific negotiation experience of a foreigner with an Italian counterpart. In line with Nielsen et al. (2020) recommendations, the responses were classified, and relevant quotations were used to triangulate and deepen our theoretical understanding and interpretation of the quantitative results.

\section{Data analysis}

The sample size of the quantitative database (214 observations and 53 variables) immediately ruled out the possibility of using the whole set of variables to perform any statistical analysis. Therefore, we initially needed to reduce the variables to a subset that we could use to identify meaningful clusters of respondents. Basing our selection on theoretical grounds, we chose eight variables that best described the four negotiation principles proposed by Fisher, Ury, and Patton (1981): separate people from the problem, focus on interest (not positions), invent options for mutual gain, and insist on objective criteria (see Table 1).

According to the theoretical framework developed by Fisher, Ury, and Patton (1981), the negotiator that seeks integrative agreements while maintaining the relationship with the counterpart should not treat the other party as rival, not let his/her emotions to dominate the process, try to explore and understand the expectations of the other party, not focusing excessively on the first proposal, but rather integrating mutual interests to reach a satisfactory agreement for both parties. Moreover, they suggest that the negotiation process should be based on creating value first, and then use objective considerations and technical criteria to distribute the value.

We then applied latent class analysis (hereafter LCA), a special case within the more general class of latent variable models (Bartholomew, Knott, \& Moustaki, 2011). The most distinctive feature of these models is that researchers cannot directly observe some of their variables, either because the variables are difficult or impossible to measure, or simply because the researchers did not measure them. These latent variables, nonetheless, form a critical part of the model and strongly influence the behavior of individuals. Although this set of variables cannot be observed, the researcher does have access to another set of observed, manifest variables that potentially correlate with the latent variables (Goodman, 1974).

In LCA, the latent variable is categorical, comprising a set of latent classes with multinomial distribution, which are measured by observed indicators. The overall objective of performing LCA on a set of variables is to derive a batch of latent classes (or 'clusters') that represents the response pattern in the data and gives a sense of the prevalence of each latent class (Collins \& Lanza, 2010).

Following Collins and Lanza (2010), we assume the existence of a latent categorical variable $g$ that can take on $G$ possible values:

$$
g=\{1,2, \ldots, G\}
$$

These values themselves neither have a special meaning nor represent an ordinal scale; they are just labels. In our case, they are associated with different negotiation behaviors.

We cannot observe $g$ directly, but we have access to the manifest categorical variables $j=1, \ldots$, $J$ - (in our case, the answers to the questions in the survey about cross-cultural negotiation). Each categorical variable $j$ has $k_{j}=1, \ldots, K_{j}$ response categories. $^{6}$

\footnotetext{
${ }^{5}$ Appendix 4 reports the questions used to recompile the information of our qualitative database.

${ }^{6}$ The model can accommodate different numbers of possible responses for each variable. In our case, for most variables, $k_{j}=3$, with $j=\{1,2,3\}=\{$ Yes, Do not know/Not sure, No $\}$. However, a few variables have more possible responses. For example, the variable Counterpart, which corresponds to the question 'How do they treat the counterpart?,' has six possible responses: $k_{\text {Counterpart }}=\{1, \ldots, 6\}=\{$ Friend, Colleague, Rival, Impersonal, Other, Do not know/Not sure $\}$.
} 
Table 1. Variable selection according to principles of negotiation (Fisher, Ury, \& Patton, 1981)

\begin{tabular}{|c|c|c|c|}
\hline $\begin{array}{l}\text { Fisher-Ury-Patton } \\
\text { principles }\end{array}$ & Variable & Variable definition & Answers \\
\hline \multirow{9}{*}{$\begin{array}{l}\text { Separate the } \\
\text { people from the } \\
\text { problem }\end{array}$} & \multirow[t]{6}{*}{ Counterpart } & \multirow{6}{*}{$\begin{array}{l}\text { How do they treat the } \\
\text { counterpart? }\end{array}$} & Friend \\
\hline & & & Colleague \\
\hline & & & Rival \\
\hline & & & Impersonal \\
\hline & & & Other \\
\hline & & & Don't know/Not sure \\
\hline & \multirow[t]{3}{*}{ Emotions } & \multirow{3}{*}{$\begin{array}{l}\text { Do they express emotions in } \\
\text { negotiations? }\end{array}$} & Yes (emotional) \\
\hline & & & Don't know/Not sure \\
\hline & & & No (rational) \\
\hline \multirow[t]{6}{*}{$\begin{array}{l}\text { Focus on interest } \\
\text { (not position) }\end{array}$} & \multirow[t]{3}{*}{ Expectations } & \multirow{3}{*}{$\begin{array}{l}\text { Do they try to know and fulfill } \\
\text { the expectations of the } \\
\text { other party? }\end{array}$} & $\begin{array}{l}\text { Yes (they explore the interests of the } \\
\text { other party) }\end{array}$ \\
\hline & & & Don't know/Not sure \\
\hline & & & $\begin{array}{l}\text { No (they concentrate just on their } \\
\text { own interests) }\end{array}$ \\
\hline & \multirow[t]{3}{*}{ Bargain } & \multirow{3}{*}{$\begin{array}{l}\text { Is it essentially a bargaining } \\
\text { process based on the initial } \\
\text { proposal? }\end{array}$} & $\begin{array}{l}\text { Yes (they insist on the original } \\
\text { proposal for a good while) }\end{array}$ \\
\hline & & & Don't know/Not sure \\
\hline & & & $\begin{array}{l}\text { No (they try to integrate mutual } \\
\text { interests, to create mutual value } \\
\text { first) }\end{array}$ \\
\hline \multirow{6}{*}{$\begin{array}{l}\text { Invent options for } \\
\text { mutual gain }\end{array}$} & \multirow[t]{3}{*}{ Mutuality } & \multirow{3}{*}{$\begin{array}{l}\text { Does first proposal include } \\
\text { mutual interests? }\end{array}$} & Yes (mutual interests) \\
\hline & & & Don't know/Not sure \\
\hline & & & No (only individual interests) \\
\hline & \multirow[t]{3}{*}{ Negotiation } & \multirow[t]{3}{*}{$\begin{array}{l}\text { How do they see the process } \\
\text { of negotiation? }\end{array}$} & $\begin{array}{l}\text { Distribute value (distributive, } \\
\text { traditional, positional, zero-sum } \\
\text { game) }\end{array}$ \\
\hline & & & Don't know/Not sure \\
\hline & & & $\begin{array}{l}\text { Create and distribute value } \\
\text { (integrative, principled, } \\
\text { interest-based, mutual gains) }\end{array}$ \\
\hline \multirow[t]{6}{*}{$\begin{array}{l}\text { Insist on objective } \\
\text { criteria }\end{array}$} & \multirow[t]{3}{*}{ Objectivity } & \multirow[t]{3}{*}{$\begin{array}{l}\text { Do they use objective criteria } \\
\text { to justify offers? }\end{array}$} & $\begin{array}{l}\text { Yes (they use data, technical } \\
\text { considerations, fact-based } \\
\text { proposals) }\end{array}$ \\
\hline & & & Don't know/Not sure \\
\hline & & & $\begin{array}{l}\text { No (they use purely subjective } \\
\text { bargaining, haggling) }\end{array}$ \\
\hline & \multirow[t]{3}{*}{ Technicians } & \multirow{3}{*}{$\begin{array}{l}\text { Are technicians involved in the } \\
\text { negotiation process? }\end{array}$} & Yes (technical criteria are key) \\
\hline & & & Don't know/Not sure \\
\hline & & & $\begin{array}{l}\text { No (little influence of technical staff } \\
\text { in negotiation) }\end{array}$ \\
\hline
\end{tabular}


We define $x=\left(k_{1}, \ldots, k_{j}\right)$ as a complete response pattern, namely a vector of responses to the $J$ manifest categorical variables. Let $x_{j}$ represent element $j$ of a response pattern $x$.

On the assumption that the manifest variables are mutually independent of each other, and conditional on being a member of group $g$, the probability density of an observed response pattern $x$ can be written as:

$$
x \mid g \sim \prod_{j=1}^{J} \times \prod_{k_{j}=1}^{K_{j}} P_{j, k_{j} \mid g}^{1\left(x_{j}=k_{j}\right)}
$$

where $1\left(x_{j}=k_{j}\right)$ represents an indicator variable that equals 1 when the response to variable $j$ is the $k_{j}$-th possible answer, and 0 otherwise. $P_{j, k_{j} \mid g}$ represents the probability that the categorical variable takes on the $k_{j}$-th value and acts as the probability for each possible response. The index $g$ explicitly refers to the fact that these probabilities differ among the latent classes.

One fundamental assumption of latent class models is the local independence assumption, which implies, conditionally on the latent variables, that the observed variables are independent. ${ }^{7}$ This assumption makes LCA a relatively simple model to estimate. If membership in the different groups acts as another random variable, then the full joint probability distribution is defined as:

$$
x \sim \sum_{g=1}^{G} \pi_{g} \prod_{j=1}^{J} \times \prod_{k_{j}=1}^{K_{j}} P_{j, k_{j} \mid g}^{1\left(x_{j}=k_{j}\right)}
$$

where $\pi_{g}$ represents the probability of belonging to class $g$, the so-called mixing proportion from cluster analysis.

Maximum likelihood (ML) estimates the parameters of the model based on the data and results in two outputs:

- Latent class prevalences: The $\pi_{g}$ values represent the probabilities of membership in the different classes. They measure the importance or prevalence of the different clusters in the population. ${ }^{8}$

- Item-response probabilities: The $P_{j, k_{j} \mid g}$ values are calculated for each group and for each question in the survey and express the relation between each observed variable and each latent class. They represent a vector of probabilities that measures the probability of a specific pattern of answers to the different questions. The different responses allow for the different classes to be profiled. ${ }^{9}$

All the formulas written above remain conditional on knowing the number of latent classes. In practice, of course, the number of classes remains unknown in advance, and one must proceed by fitting models with different numbers of classes, starting with a model with no cluster structure whatsoever (a model in which the number of classes equals 1). Then the researcher must try more complicated models, with two or more classes. The Bayesian information criterion (BIC) selects the best model as a transformation (a penalized version) of the log-likelihood statistic and is generally the most appropriate goodness-of-fit criterion for basic latent class models (Collins \&

\footnotetext{
${ }^{7}$ The local independence assumption does not imply that, in a data set, the observed variables are independent, as in fact it is the relations among the observed variables that are explained by the latent classes. Independence is rather assumed to hold only within each latent class (and therefore it is called 'local') (Collins \& Lanza, 2010).

${ }^{8}$ The latent classes are mutually exclusive and exhaustive, which means that each individual is a member of one and only one latent class. Therefore, $\sum_{g=1}^{G} \pi_{g}=1$.

${ }^{9}$ Because each individual provides one and only one response to variable $j$, the vector of item-response probabilities for a particular variable conditional on a particular latent class $g$ always sums to $1: \sum_{k_{j}=1}^{K_{j}} P_{j, k_{j} \mid g}=1$.
} 
Lanza, 2010; Linzer \& Lewis, 2011), as it allows picking a model that fits the data well, while remaining parsimonious and protecting against overfitting the dataset:

$$
\mathrm{BIC}=-2 \times L L+\log (N) \times M
$$

where $L L$ represents the log-likelihood statistic, $M$ represents the number of parameters in the model, and $N$ represents the sample size. The best model is the one that achieves the smallest BIC value.

As we are interested in whether country culture predicts membership in the latent classes, we introduce a covariate Country $=\{1,2\}=\{$ ITA, USA $\}$ into the latent class model. Covariates can be incorporated into LCA using a logistic regression approach (Collins \& Lanza, 2010). The framework is the same as previously described. In addition, we introduce a covariate $V$, to be used to predict latent class membership. Then the latent class model can be expressed as follows:

$$
x \mid v \sim \sum_{g=1}^{G} \pi_{g}(v) \prod_{j=1}^{J} \times \prod_{k_{j}=1}^{K_{j}} P_{j, k_{j} \mid g}^{1\left(x_{j}=k_{j}\right)}
$$

where $\pi_{g}(v)$ is a standard baseline-category multinomial logistic model. In LCA with covariates, the item-response probabilities are still estimated; latent class prevalences can be easily calculated from the estimated parameters. ${ }^{10}$

\section{Results}

The first step of LCA is to define the optimal number of clusters. Table 2 reports the fit statistics for this clustering process, comparing potential candidate models with one to four clusters. The table reports likelihood statistics, BICs, numbers of parameters, and residual degrees of freedom. In our case, the model with three classes has the smallest BIC value and therefore represents the best description of the data.

Table 3 shows the results of estimating the LCA model with country as covariate (Linzer \& Lewis, 2011), which identify three distinct classes of negotiation prototypes.

Negotiators who fall under Class 1 (33.45\% of observations) tend to practice distributive negotiation: $55 \%$ of them consider the counterpart in negotiation as a rival, and they seem to concentrate only on their own interests, neither trying to understand and fulfill the expectations of the other party $(80 \%)$ nor including mutual interests in their first proposal $(68 \%)$. In $81 \%$ of the cases, they are perceived as understanding the process of negotiation as a distributive, zerosum game. On the other hand, negotiators who fit into Class 2 (29.59\% of observations) and Class $3(36.96 \%)$ tend to practice integrative negotiation. They extensively use objective criteria and technical considerations to justify their offers ( $80 \%$ for Class 2 and $90 \%$ for Class 3), and their counterparts largely recognize that they understand negotiation as an interest-based process to create and distribute value for mutual gains (76 and 54\% for Classes 2 and 3, respectively).

Interestingly, although the overall frequencies of each class seem rather uniformly distributed, as soon as we consider the effect of the variable Country, the picture changes significantly. An Italian negotiator has a $51.17 \%$ probability of belonging to Class 1 and a $43.42 \%$ probability of belonging to Class 2, whereas an American negotiator has an $89.81 \%$ probability of fitting into Class 3. This pattern is mirrored when we consider each class separately: for Classes 1 and 2, the probability of a member's being Italian is above $90 \%$, and for Class 3, the probability of a

\footnotetext{
${ }^{10}$ With a single covariate $V$, latent class prevalences can be expressed as $\pi_{g}(v)=e^{\beta_{0 g}+\beta_{1 g} v} /\left(1+\sum_{g /=1}^{G-1} e^{\beta_{0 g}+\beta_{1 g} v}\right)$ for $g^{\prime}=1, \ldots, G-1$ (the logistic regression requires to choose one category of the criterion variable as the reference category and generates an estimate of the effect for each latent class in comparison with the reference one).
} 
Table 2. Model selection with 1, 2, 3, or 4 clusters

\begin{tabular}{lcccc}
\hline Model & LL & BIC & Number of estimated parameters & Residual degrees of freedom \\
\hline 1-Cluster & $-1,887.21$ & $3,876.37$ & 19 & 195 \\
\hline 2-Cluster & $-1,701.44$ & $3,612.15$ & 39 & 175 \\
\hline 3-Cluster & $-1,630.31$ & $3,577.21^{\text {a }}$ & 59 & 155 \\
\hline 4-Cluster & $-1,579.41$ & $3,582.74$ & 79 & 135 \\
\hline
\end{tabular}

${ }^{\mathrm{a}}$ This is the preferred model according to the BIC criterion (lowest BIC).

member's being American is also around 90\%. Clearly, the variable Country has a significant impact on clustering, and the two cultural groups differ in negotiation styles and strategies.

On these grounds, we can reckon that Proposition 1 is partially supported by our data, as we identify both the distributive and the integrative negotiation prototypes for Italy, but only the integrative one for the USA - a finding that has precedents in the literature (e.g., Pruitt, 1981). ${ }^{11}$ The fact that both Classes 2 and 3 tend toward integrative negotiation but are separate clusters with distinctly national membership patterns indicates that negotiation prototypes are not completely homogeneous across different cultures, in accordance with Proposition 2.

It is important to notice here that, despite sharing a common history, religion, ancestry, and language, Italy is not totally homogeneous, with differences in values, attitudes, and behaviors between North and South (see, e.g., Clò, 2006). In his online platform, which allows users to compare and contrast the cultural characteristics of countries, Hofstede recognizes this difference ${ }^{12}$ (in particular, on the dimensions of power distance and individualism), which makes Northern Italy more similar to the USA. Our databases do not include information on the regional origin of the Italian counterparts with whom our respondents negotiated, so we adopt Hofstede's general list of Italian cultural features. And indeed, both Classes 1 and 2 present intriguing idiosyncrasies that substantially differentiate them from the predominantly North American Class 3.

First, negotiators of both Classes 1 and 2 are reported to express emotions during the negotiation process (75 and 60\%, respectively). Given that these two classes are mainly composed of Italian individuals, this result suggests that emotionality is an embedded cultural characteristic that persists in negotiation, whichever strategy is used. In their review of negotiation behaviors linked to peculiar cultural traits, Hofstede et al. (2012) state that negotiators from uncertainty avoiding cultures tend to have an emotional style of negotiation and it is important for them to make sure that their counterpart understand and are aware of their feelings (Hofstede, 2001). The extensive expression of emotions during the negotiation process displayed by Italians can be a reflection of their relatively high uncertainty avoidance culture (Italy ranks 28 out of 63 countries on this dimension of the Hofstede's model, whereas the USA ranks $52^{13}$ ).

The topic of emotions is also often mentioned in our qualitative database. For instance, a Colombian director of a legal office who has an Italian woman client in Bogotá commented that '[Italians] are very expressive ... they laugh or cry or scream when they feel it and express everything they think and feel without fears' (Interview 18). Emotions seem to have an ambiguous impact on the negotiation process, as they can manifest sometimes as kindness and

\footnotetext{
${ }^{11}$ We tried to run LCA with four clusters to verify whether a cluster would emerge with distributive negotiation behavior and a predominance of American individuals. However, what appeared was a third, prevalently Italian, negotiation prototype that represents an 'intermediate' style between the integrative and the distributive ones, in the sense that, for most of the questions, the counterpart could not clearly determine the dominant negotiation behavior (most answers fell in the 'Do not know/Not sure' category). Results are available upon request.

${ }^{12}$ https://www.hofstede-insights.com/country-comparison/italy/.

${ }^{13}$ Data on positional rankings of Italy and USA on the Hofstede's cultural dimensions are reported in Appendix 1.
} 
Table 3. Parameter estimates for 3-class model using Country as covariate

\begin{tabular}{|c|c|c|c|c|c|c|c|}
\hline Principle & Variable & Question & $\begin{array}{l}\text { No. of } \\
\text { levels }\end{array}$ & Levels & Class 1 & Class 2 & Class 3 \\
\hline \multirow{9}{*}{$\begin{array}{l}\text { Separate people } \\
\text { from problems }\end{array}$} & \multirow[t]{6}{*}{ Counterpart } & \multirow[t]{6}{*}{ How do they treat the counterpart? } & \multirow[t]{6}{*}{6} & Friend & .18 & .14 & .16 \\
\hline & & & & Colleague & .08 & .58 & .26 \\
\hline & & & & Rival & $.55^{\mathrm{a}}$ & .06 & .09 \\
\hline & & & & Impersonal & .03 & .00 & .44 \\
\hline & & & & Other & .00 & .00 & .03 \\
\hline & & & & Don't know & .16 & .22 & .02 \\
\hline & \multirow[t]{3}{*}{ Emotions } & \multirow{3}{*}{$\begin{array}{l}\text { Do they express emotions in } \\
\text { negotiations? }\end{array}$} & \multirow[t]{3}{*}{3} & Yes (emotional) & .75 & .60 & .19 \\
\hline & & & & Don't know & .23 & .38 & .01 \\
\hline & & & & No (rational) & .02 & .02 & .80 \\
\hline \multirow[t]{6}{*}{ Focus on interests } & \multirow[t]{3}{*}{ Expectations } & \multirow[t]{3}{*}{$\begin{array}{l}\text { Do they try to know and fulfill the } \\
\text { expectations of the other party? }\end{array}$} & \multirow[t]{3}{*}{3} & $\begin{array}{l}\text { Yes (they explore the interests of the other } \\
\text { party) }\end{array}$ & .07 & .70 & .48 \\
\hline & & & & Don't know & .14 & .30 & .10 \\
\hline & & & & $\begin{array}{l}\text { No (they concentrate just on their own } \\
\text { interests) }\end{array}$ & .79 & .00 & .42 \\
\hline & \multirow[t]{3}{*}{ Bargain } & \multirow[t]{3}{*}{$\begin{array}{l}\text { Is it essentially a bargaining process } \\
\text { based on the initial proposal? }\end{array}$} & \multirow[t]{3}{*}{3} & $\begin{array}{l}\text { Yes (they insist on the original proposal for } \\
\text { a good while) }\end{array}$ & .60 & .37 & .29 \\
\hline & & & & Don't know & .40 & .24 & .10 \\
\hline & & & & $\begin{array}{l}\text { No (they try to integrate mutual interests, } \\
\text { to create mutual value first) }\end{array}$ & .00 & .39 & .61 \\
\hline \multirow{5}{*}{$\begin{array}{l}\text { Invent options for } \\
\text { mutual gain }\end{array}$} & \multirow[t]{3}{*}{ Mutuality } & \multirow{3}{*}{$\begin{array}{l}\text { Does first proposal include mutual } \\
\text { interests? }\end{array}$} & \multirow[t]{3}{*}{3} & Yes (mutual interests) & .02 & .50 & .30 \\
\hline & & & & Don't know & .30 & .46 & .44 \\
\hline & & & & No (only individual interests) & .68 & .04 & .26 \\
\hline & \multirow[t]{2}{*}{ Negotiation } & \multirow[t]{2}{*}{$\begin{array}{l}\text { How do they understand the } \\
\text { process of negotiation? }\end{array}$} & \multirow[t]{2}{*}{3} & $\begin{array}{l}\text { Distribute value (distributive, traditional, } \\
\text { positional, zero-sum game) }\end{array}$ & .80 & .07 & .40 \\
\hline & & & & Don't know & .18 & .17 & .06 \\
\hline
\end{tabular}




\begin{tabular}{|c|c|c|c|c|c|c|c|}
\hline & & & & $\begin{array}{l}\text { Create and distribute value (integrative, } \\
\text { principled, interest-based, mutual gains) }\end{array}$ & .02 & .76 & .54 \\
\hline \multirow{6}{*}{$\begin{array}{l}\text { Insist on objective } \\
\text { criteria }\end{array}$} & \multirow[t]{3}{*}{ Technicians } & \multirow{3}{*}{$\begin{array}{l}\text { Are technicians involved in the } \\
\text { negotiation process? }\end{array}$} & \multirow[t]{3}{*}{3} & Yes (technical criteria are key) & .15 & .13 & .52 \\
\hline & & & & Don't know & .58 & .48 & .20 \\
\hline & & & & $\begin{array}{l}\text { No (little influence of technical staff in } \\
\text { negotiation) }\end{array}$ & .27 & .39 & .23 \\
\hline & \multirow[t]{3}{*}{ Objectivity } & \multirow[t]{3}{*}{$\begin{array}{l}\text { Do they use objective criteria to } \\
\text { justify offers? }\end{array}$} & \multirow[t]{3}{*}{3} & $\begin{array}{l}\text { Yes (they use data, technical } \\
\text { considerations, fact-based proposals) }\end{array}$ & .12 & .80 & .90 \\
\hline & & & & Don't know & .23 & .17 & .03 \\
\hline & & & & $\begin{array}{l}\text { No (they use purely subjective bargaining, } \\
\text { haggling) }\end{array}$ & .65 & .03 & .07 \\
\hline \multicolumn{5}{|l|}{ Frequency of class } & .33 & .3 & .37 \\
\hline \multicolumn{5}{|c|}{$\operatorname{Pr}($ Class $=g \mid$ Country $=I T A)$} & .51 & .43 & .06 \\
\hline \multicolumn{5}{|c|}{$\operatorname{Pr}($ Class $=g \mid$ Country $=$ USA $)$} & .04 & .06 & .90 \\
\hline \multicolumn{5}{|c|}{$\operatorname{Pr}($ Country $=I T A \mid$ Class $=g)$} & .96 & .92 & .09 \\
\hline \multicolumn{5}{|c|}{$\operatorname{Pr}($ Country $=$ USA $\mid$ Class $=g)$} & .04 & .08 & .91 \\
\hline \multicolumn{4}{|c|}{ Maximum log-likelihood (LL) } & \multicolumn{4}{|c|}{$-1,567.38$} \\
\hline \multicolumn{4}{|l|}{$\mathrm{BIC}$} & \multicolumn{4}{|c|}{$3,462.09$} \\
\hline \multicolumn{4}{|c|}{ Number of estimated parameters } & \multicolumn{4}{|c|}{61} \\
\hline \multicolumn{4}{|c|}{ Residual degrees of freedom } & \multicolumn{4}{|c|}{153} \\
\hline
\end{tabular}

${ }^{a}$ Conditional probabilities $>.50$ in bold, to facilitate interpretation. 
friendship and sometimes as aggressiveness and lack of control. A Mexican interviewee reported, '[Italians] are very expressive, their gestural and body language is very evident; when they discuss, the situation can turn tense due to the volume of their voice and the intention of the message ... Their intense emotions are culturally natural; their "openness" can degenerate into hostility but also [can manifest] in an affectionate, sympathetic, or even "convincing" gesture' (Interview 86). This trait is commonly recognized by Italians themselves. An Italian owner of a restaurant in Spain, for example, stated that 'The Italians and Spaniards have a very similar character, we are visceral, impulsive ...' (Interview 42).

In general, this type of emotional negotiator perceives negotiation meetings as an occasion for social contact; participants tend to discuss generalities, and technicians seldom participate in the process. In our data, for both Classes 1 and 2, negotiating counterparts seem unsure whether or not technicians are involved in the negotiation process (58 and 48\%, respectively).

It is also not very clear whether negotiators in Classes 1 and 2 essentially perceive the negotiation as a bargaining process. On the one hand, in Class 1, 60\% of individuals seem to base their strategy on haggling, whereas in the rest of the cases it is hard for the counterpart to assess this attitude. On the other hand, in Class 2, negotiators are almost equally distributed, with $37 \%$ of them insisting on their initial proposal and showing a bargaining attitude, and 39\% of them trying to integrate mutual interests into the negotiation and pursuing the creation of shared value. This lack of clarity is reflected also in our qualitative database. A Colombian sales manager stated that 'with them [Italians] there is not much bargaining possibility' but also that Italians 'are flexible to the extent possible, friendly, open, and avoid conflict and problems' (Interview 5). Another Colombian interviewee, who oversaw sales coordination with Mediterranean Europe, commented regarding negotiating with Italian counterparts: 'Sometimes there was haggling, but in general terms it was a very well-structured process, [...]. Basically, intermediate points between the two positions were achieved, [and] new clauses were drafted, taking the obligations of both parties to logical points, seeking that the agreement and the cooperation of the companies really occurred without damages to any of them' (Interview 19). The apparent coexistence of distributive and integrative strategies among Italian negotiators may explain this ambivalence. In contrast, the direct assessment of how the counterpart understands and handles the negotiation process differentiates the two styles explicitly: $81 \%$ of individuals in Class 1 are perceived as distributive and $76 \%$ of those in Class 2 are recognized as integrative.

The North American cluster shows predominantly integrative attitudes, even if some of the behaviors are distributive. In particular, $44 \%$ of individuals in Class 3 are perceived to treat the counterpart impersonally and only $26 \%$ as a colleague. Moreover, for the negotiation counterparts it seems to be difficult to assess whether Americans try to explore, understand, and fulfill the expectations of the other party during the negotiation process ( $48 \%$ say yes and $42 \%$ no) and whether they incorporate mutual interests at the beginning of the negotiation ( $44 \%$ are not sure). When asked directly to assess how the US counterparts understand the negotiation process, $54 \%$ of the respondents perceive them as integrative and problem-solving, whereas $40 \%$ interpret them as merely interested in distributing value.

The United States are ranked as the most individualistic country according to the Hofstede's framework and these ambiguous results can be a manifestation of this cultural trait. In fact, Hofstede et al. (2012) state that negotiators from highly individualistic societies tend to conduct the process having clear in mind their own personal interests (whatever those interests are), whereas they might pose less emphasis on relationship building (Hofstede, 2001). This trait could make the negotiating counterpart doubt whether his/her interests and perspectives are indeed taken into consideration by the US negotiators.

In summary, our first cluster identified through LCA clearly represents distributive negotiators, whereas the second and third clusters represent integrative negotiators (Table 4). The distributive negotiator is the classical type, who does not apply the negotiation principles proposed by Fisher, Ury, and Patton (1981). This negotiator conceives negotiation as a zero- 
Table 4. Summary of research findings

\begin{tabular}{|c|c|c|c|}
\hline $\begin{array}{l}\text { Negotiation } \\
\text { principles }\end{array}$ & $\begin{array}{c}\text { Class } 1 \\
\text { Distributive } \\
\text { ITA }\end{array}$ & $\begin{array}{c}\text { Class } 2 \\
\text { Emotional integrative } \\
\text { ITA }\end{array}$ & $\begin{array}{c}\text { Class } 3 \\
\text { Impersonal Integrative } \\
\text { USA }\end{array}$ \\
\hline \multirow[t]{2}{*}{$\begin{array}{l}\text { Separate } \\
\text { people from } \\
\text { problem }\end{array}$} & $\begin{array}{l}\text { Tend to treat the } \\
\text { negotiating } \\
\text { counterpart as a rival. }\end{array}$ & $\begin{array}{l}\text { Tend to treat the negotiating } \\
\text { counterpart as a } \\
\text { colleague. }\end{array}$ & $\begin{array}{l}\text { Tend to treat the negotiating } \\
\text { counterpart impersonally } \\
\text { or sometimes as a } \\
\text { colleague. }\end{array}$ \\
\hline & $\begin{array}{l}\text { Tend to express emotions } \\
\text { during the negotiation } \\
\text { process. }\end{array}$ & $\begin{array}{l}\text { Tend to express emotions } \\
\text { during the negotiation } \\
\text { process. }\end{array}$ & $\begin{array}{l}\text { Tend to avoid expressing } \\
\text { emotion during the } \\
\text { negotiation process. }\end{array}$ \\
\hline \multirow[t]{2}{*}{$\begin{array}{l}\text { Focus on } \\
\text { interests }\end{array}$} & $\begin{array}{l}\text { Tend to focus only on } \\
\text { their own interests } \\
\text { during the } \\
\text { negotiation. }\end{array}$ & $\begin{array}{l}\text { Tend to explore the interests } \\
\text { of the other party during } \\
\text { the negotiation. }\end{array}$ & $\begin{array}{l}\text { Unclear prevalent behavior } \\
\text { with respect to } \\
\text { exploration of other } \\
\text { party's interests. }\end{array}$ \\
\hline & $\begin{array}{l}\text { Tend to insist on their } \\
\text { original proposal } \\
\text { during the negotiation } \\
\text { process. }\end{array}$ & $\begin{array}{l}\text { Unclear prevalent behavior } \\
\text { with respect to the focus } \\
\text { and insistence on the first } \\
\text { proposal during the } \\
\text { negotiation process. }\end{array}$ & $\begin{array}{l}\text { Tend to integrate mutual } \\
\text { interests without too } \\
\text { much insistence on first } \\
\text { proposal during the } \\
\text { negotiation process. }\end{array}$ \\
\hline \multirow[t]{2}{*}{$\begin{array}{l}\text { Invent options } \\
\text { for mutual } \\
\text { gains }\end{array}$} & $\begin{array}{l}\text { First proposal tends to } \\
\text { include only individual } \\
\text { interests. }\end{array}$ & $\begin{array}{l}\text { First proposal tends to } \\
\text { include mutual interests. }\end{array}$ & $\begin{array}{l}\text { Unclear prevalent character } \\
\text { of first proposal in terms } \\
\text { of mutual or individual } \\
\text { interests' inclusion. }\end{array}$ \\
\hline & $\begin{array}{l}\text { Tend to understand the } \\
\text { objective of the } \\
\text { negotiation process as } \\
\text { distribute value } \\
\text { (distributive). }\end{array}$ & $\begin{array}{l}\text { Tend to understand the } \\
\text { objective of the } \\
\text { negotiation process as } \\
\text { create and distribute value } \\
\text { (integrative). }\end{array}$ & $\begin{array}{l}\text { Tend to understand the } \\
\text { objective of the } \\
\text { negotiation process as } \\
\text { create and distribute } \\
\text { value (integrative). }\end{array}$ \\
\hline \multirow[t]{2}{*}{$\begin{array}{l}\text { Insist on } \\
\text { objective } \\
\text { criteria }\end{array}$} & $\begin{array}{l}\text { Unclear prevalence or } \\
\text { influence of technical } \\
\text { staff and technical } \\
\text { criteria during the } \\
\text { negotiation process. }\end{array}$ & $\begin{array}{l}\text { Unclear prevalence or } \\
\text { influence of technical staff } \\
\text { and technical criteria } \\
\text { during the negotiation } \\
\text { process. }\end{array}$ & $\begin{array}{l}\text { Technical criteria tend to be } \\
\text { important during the } \\
\text { negotiation process. }\end{array}$ \\
\hline & $\begin{array}{l}\text { Tend to use pure } \\
\text { subjective bargaining } \\
\text { during the negotiation } \\
\text { process. }\end{array}$ & $\begin{array}{l}\text { Tend to use technical } \\
\text { considerations and } \\
\text { fact-based proposal during } \\
\text { the negotiation process. }\end{array}$ & $\begin{array}{l}\text { Tend to use technical } \\
\text { considerations and } \\
\text { fact-based proposal } \\
\text { during the negotiation } \\
\text { process. }\end{array}$ \\
\hline
\end{tabular}

sum game and the counterpart as a rival to defeat, does not explore the interests of the other party to make integrative, mutually beneficial offers, induces a process of bargaining and haggling (instead of using objective criteria to distribute value), and uses emotions during the negotiation process. The second cluster represents a new type of integrative negotiator found in Italy. This negotiator seems to treat the counterpart as a colleague (rather than as a rival or impersonally), explores interests before making a proposal for mutual benefits, is strongly oriented to mutual value creation, expresses emotions, and uses objective criteria, even though he or she may end up bargaining if the situation evolves in such a way. The third type of negotiator (mainly American) also displays integrative behaviors, applying objective and technical criteria and avoiding haggling, but is less oriented toward exploring the interests of the other side, is impersonal, and avoids expressing emotions.

On the one hand, our analysis confirms that US individuals tend to take an integrative approach to negotiation (e.g., Brett, Adair, Lempereur, Okumura, Shikhirev, and Tinsley, 1998). The 
American culture is characterized by fairly low power distance and medium uncertainty avoidance (Hofstede, 2001), high individualism and results orientation (Dorfman, Javidan, Hanges, Dastmalchian, \& House, 2012), and low-context communication and monochronicity (Hall, 1976), in spite of the efficiency of a multitask polychronic process (Brett et al., 1998). American negotiators are said to feel relatively entitled to make proposals during the process, to be eager to explore trade-offs and alternatives, and to avoid 'leaving money on the table.' Such behaviors can help build options for mutual gains. However, our results also highlight some distributive features of US negotiators, suggesting that US negotiation strategy requires more specific analysis.

On the other hand, the Italian culture scores in the middle zone in power distance and high in uncertainty avoidance (Hofstede, 2001), suggesting a certain formality in negotiations, in both role definition and detailed planning. High uncertainty avoidance is also related to the emotional style of negotiation highlighted in the analysis for Italian individuals, regardless of the negotiation strategy adopted. Italian society is also characterized by high masculinity (Hofstede, 2001), which entails a certain propensity toward competition that manifests in distributive negotiation and is necessary to obtain better economic results in the second stage of the integrative strategy.

\section{Discussion}

Our results confirm the general validity of the distributive/integrative negotiation framework (Fisher et al., 1981; Walton \& McKersie, 1965). It is in line with earlier and recent studies that supported this theoretical model even for multicultural contexts (e.g., Graham, Mintu, \& Rodgers, 1994). Nevertheless, similar to previous researchers, we also find some peculiarities related to different cultural backgrounds (Caputo et al., 2019a; Metcalf, Bird, Shankarmahesh, Aycan, Larimo, \& Valdelamar, 2006). In particular, we identify some nuances for the integrative negotiation paradigm that seem to be related to cultural traits in the context of international negotiations. This opens space for a better understanding of the complexities related to intercultural negotiations, even for Western countries that are not considered so culturally distant, such as the United States and Italy.

From the analysis, it clearly emerges that Italian people are in general very passionate and it is culturally acceptable to express emotions; indeed, not doing so is considered dishonest or disingenuous, and the attempt to be detached is perceived as a form of deception. This cultural value leads to an extensive use of varying voice tones and body language: Italians are used to highcontext communication (Hall, 1976).

Our finding of both types of negotiators in Italy aligns with the picture presented by Cominelli and Lucchiari (2017) and Caputo and Valenza (2019), who identify a continuum that ranges from 'Competing' (a conflict management style that implies a win-lose perspective) to 'Collaborating' (a view of conflicts as problems to be solved jointly, which means searching for a win-win solution). This divide in the Italian results on negotiation styles could mirror Italy's strong cultural differentiation between North and South (Clò, 2006) - a possibility that could be further examined by comparing data that include negotiators' regional provenance (Kaasa, Vadi, \& Varblane, 2014).

Our results further shed light on a substantive difference between Italian and American negotiators. Indeed, one of our interviewees pointed out this feature straightforwardly: 'The Italian is undoubtedly a kind person to negotiate with, but absolutely different from the American type, for example, which is faster, more practical in the negotiation. With them [Italians] there are a few more steps ... The negotiation and the challenge are a little more sentimental' (Interview 17). These results allow us to reject the hypothesis of homogeneity in negotiation strategies and styles across different cultural clusters, even within Western culture. ${ }^{14}$

\footnotetext{
${ }^{14}$ Similar results, although with a stronger prevalence of the distributive prototype over the integrative one, were established for a Latin American cluster (Ogliastri \& Quintanilla, 2012), which shares some cultural similarities with the Latin European one (Hofstede, 2001; Ogliastri et al., 1999).
} 
In addition, in what could be another management lesson from Italy, the main finding of our analysis seems to yield a new 'emotional integrative' negotiator prototype, one that merges integrative and emotional features. Posthuma (2012) posits that we need research on emotions - not just cognitions and behaviors - to understand and facilitate effective negotiations, and the use of emotions may be positive from a managerial perspective (Gunkel, Schlaegel, \& Taras, 2016; Kopelman \& Rosette, 2008). In a meta-analysis, Sharma, Bottom, and Elfenbein find that individuals with strong emotional intelligence 'achieve lower economic outcomes, but higher psychological subjective value' (2013: 311). Emotional intelligence is an important social skill for life, but it does not produce higher economic results for a negotiator unless both counterparts demonstrate a certain ability to handle and identify emotions (Der Foo et al., 2004). The pending question is the relative economic benefit of dealing with emotions in negotiations, especially distinguishing between positive and negative ones (e.g., Luomala et al., 2015; Wong, 2020).

Recently, in discussing how to measure dignity, face, and honor cultures, Yao, Ramirez-Marin, Brett, Aslani, and Semnani-Azad (2017) included the use of emotions in negotiations as an indicator of distributive negotiation culture. Our results, however, imply that is not necessarily the case, as the new type of Italian integrative negotiator makes all the moves to increase mutual value (a key principle), but also handles emotions in a constructive way. These findings contribute to the debate over whether Latin Europe is indeed a 'dignity' culture (Fosse, Ogliastri, \& Rendon, 2017; Ogliastri, Rendón, \& Fosse, 2017); our analysis suggests that Italy does not share negotiation prototypes with the US dignity culture, and confirms Harinck, Shafa, Ellemers, and Beersma's (2013) finding that cooperative negotiation behaviors exist in honor cultures. However, our dataset does not include key details, so this remains an interesting topic for future research.

Furthermore, it is still necessary to ascertain the specific behaviors of this 'emotional integrative' negotiator prototype, as well as the outcomes the negotiator gets from the negotiation process and the relative effects of different types of emotions (Wong, 2020). This negotiator should also be distinguished from the 'soft' distributive negotiator prototype described by Fischer, Ury and Patton (1981). Students often confuse the soft negotiator with the integrative one, but their strategies are different: the soft negotiator is likeable, shows concern for the needs of the counterpart, and is willing to make sacrifices in order to get to a quick agreement, but he or she does not believe that it is possible to increase value and conceives negotiation as a distributive zero-sum game. It is crucial to find out whether the distinctive Italian 'emotional integrative' negotiation strategy leads to better outcomes: even though this prototype is clearly different from the soft one, is it competitive enough to succeed at getting a large piece of the jointly increased value?

More research is also needed to compare and contrast this new 'emotional integrative' negotiation prototype with the 'impersonal integrative' one (Harinck et al., 2013). Indeed, as a further development of this study, it would be of great interest to extend the analysis, first by including more countries of the Latin Europe and Anglo cultural clusters, and second by broadening the database to all the relevant cultural clusters validated by Gupta, Hanges, and Dorfman (2002). An enlarged study would surely lead to more robust results, allow for wider cross-cultural comparison, and support a deeper understanding of the key cultural features that bring about different attitudes, strategies, reactions, and final outcomes during the negotiation process. Moreover, it would be of great interest to incorporate interactions of negotiators from specific cultural backgrounds to study the effects on the outcomes (Cai, Wilson, \& Drake, 2000; Fosse, Ogliastri, \& Rendon, 2017). Starting from our findings, these extensions could give managers in multicultural environments a more comprehensive map of the complex world of cross-cultural negotiation and maximize the chances to reach agreements for joint gains.

\section{Conclusion}

The contributions of this study are manyfold. First, we have contributed to the cross-cultural negotiation and international management literature by complementing the global picture of 
cross-cultural negotiation differences by introducing one of the first analysis of Italian negotiators. Second, we have contributed to the cross-cultural negotiation literature by deepening our understanding of the role of culture in the selection of a negotiation strategy, as our results clearly shows how negotiators from Italy and the USA tends to choose a different style. Such results gave also light to a third, and probably most important, contribution to the field of study of crosscultural negotiation, by unveiling a third negotiation prototype that we called 'emotional integrative.' Our findings are relevant as they seem to give insight into a multifaceted nature of the original distributive versus integrative framework, where the differential importance given to emotions in certain cultures (such as the Italian vs. the American) allows for a development of a specific, nontypical, negotiation prototype, especially among integrative negotiators. This result is in line with a trend to understand relationality in cross-cultural negotiations (Cheng, Huang, \& Su, 2017; Graham, 2019; Usunier, 2018).

Even though the results and contributions of this study are interesting and, in parts, counterintuitive, a number of limitations requiring future research are present. First, our results are drawn by the accounts of past experiences of negotiating with Italian and American negotiators, and as such are unavoidably subject to perceptions and the bias of recall (Fischhoff \& Beyth, 1975). Furthermore, qualitative data collections and analyses are intrinsically affected by subjectivity, which we tried to limit by having a cross-cultural approach and adopting a diverse and large pool of informants and interviewers (Fosse, Ogliastri, \& Rendon, 2017). These issues are very common in negotiation research (Lewicki, Saunders, \& Barry, 2020), and we call for future studies to continue in methodological advancements that allow for better proxies of real negotiations. Second, our study focused on comparing only two countries (USA and Italy) and did not investigate how the negotiators' prototypes would relate to each other. Future research could address this gap by extending our research in investigating the interaction dynamics of the identified prototypes, as well as looking at more countries and cultures. Finally, similarly to Fosse, Ogliastri, and Rendon (2017) we should be careful in labeling the typical 'Italian' or 'American' as both countries have had demographic and social changes over the years that have shaped culture and negotiation style. Future research avenues could focus on a truer account of cultural diversity, for example by looking directly at individual cultural values (Caputo et al., 2019a).

Our contributions are also of practical and managerial relevance (summarized in Table 4). Our findings suggest that managers and negotiators interacting with Italian negotiators need to pay particular attention to the role played by emotions when aiming to achieve integrative agreements. Similarly, when negotiating with American negotiators, to achieve integrative agreements the focus seems to be more toward the impersonal and technical considerations of the negotiation. Finally, according to our results, training is implicated. Negotiators and managers who would like to successfully bridge across cultures and within global environments will benefit from training that is culturally focused. Indeed, training negotiators almost exclusively on American-based content, may displace efforts to successfully reach integrative agreements with other cultures, as the Italian experiences have shown. Conflict management and negotiation training packages should not only train negotiation skills, but also emotional and cultural competencies to effectively negotiate.

\section{References}

Adair, W. L., \& Brett, J. M. (2005). The negotiation dance: Time, culture, and behavioral sequences in negotiation. Organization Science, 16(1), 33-51.

Adair, W. L., Brett, J. M., Lempereur, A., Okumura, T., Shikhirev, P., Tinsley, C., \& Lytle, A. (2004). Culture and negotiation strategy. Negotiation Journal, 20(1), 87-111.

Adair, W. L., Hideg, I., \& Spence, J. R. (2013). The culturally intelligent team: The impact of team cultural intelligence and cultural heterogeneity on team shared values. Journal of Cross-Cultural Psychology, 44(6), 941-962.

Adair, W. L., Okumura, T., \& Brett, J. M. (2001). Negotiation behavior when cultures collide: The United States and Japan. Journal of Applied Psychology, 86(3), 371-385. 
Adler, N. J. (1980). Cultural synergy: The management of cross-cultural organizations. McGill University.

Adler, N. J., \& Aycan, Z. (2018). Cross-cultural interaction: What we know and what we need to know. Annual Review of Organizational Psychology and Organizational Behavior, 5(1), 307-333. https://doi.org/10.1146/annurev-orgpsych032117-104528.

Adler, N.J., \& Graham, J.L. (2017). Cross-cultural Interaction: The International Comparison Fallacy?. In: Brannen, M.Y., Mughan, T. (eds) Language in International Business. JIBS Special Collections. Palgrave Macmillan, Cham.

Aslani, S., Ramirez-Marin, J., Brett, J. M., Yao, J., Semnani-Azad, Z., Zhang, Z., ... Adair, W. L. (2016). Dignity, face, and honor cultures: A study of negotiation strategy and outcomes in three cultures. Journal of Organizational Behavior, 37 (8), 1178-1201.

Bartholomew, D. J., Knott, M., \& Moustaki, I. (2011). Latent variable models and factor analysis: A unified approach (Vol. 904). London, UK: John Wiley \& Sons.

Bourdieu, P. (1977). Outline of a theory of practice (Vol. 16). Cambridge University Press.

Brett, J. M. (2007). Negotiating globally: How to negotiate deals, resolve disputes, and make decisions across cultural boundaries. San Francisco, CA: Jossey-Bass.

Brett, J.M. (2017). Culture and negotiation strategy. Journal of Business \& Industrial Marketing, 32(4), 587-590.

Brett, J. M., Adair, W. L., Lempereur, A., Okumura, T., Shikhirev, P., \& Tinsley, C. (1998). Culture and joint gains in negotiation. Negotiation Journal (Prior to Jan 1, 2004), 14(1), 61-86.

Brett, J. M., Gunia, B. C., \& Teucher, B. M. (2017). Culture and negotiation strategy: A framework for future research. Academy of Management Perspectives, 31(4), 288-308.

Brett, J. M., \& Okumura, T. (1998). Inter- and intracultural negotiation: U.S. and Japanese negotiators. Academy of Management Journal, 41(5), 495-510. https://doi.org/10.2307/256938.

Brett, J. M., \& Thompson, L. (2016). Negotiation. Organizational Behavior and Human Decision Processes, 136, 68-79. https:// doi.org/10.1016/j.obhdp.2016.06.003.

Broome, B. J. (2017). Negotiating the nexus: Symbiotic relationship of theory and practice in conflict management. Negotiation and Conflict Management Research, 10(4, SI), 252-264. https://doi.org/10.1111/ncmr.12105.

Cai, D. A., \& Fink, E. (2002). Conflict style differences between individualists and collectivists. Communication Monographs, 69(1), 67-87. https://doi.org/10.1080/03637750216536.

Cai, D. A., Wilson, S. R., \& Drake, L. E. (2000). Culture in the context of intercultural negotiation: Individualism-collectivism and paths to integrative agreements. Human Communication Research, 26(4), 591-617. https://doi.org/10.1111/j.14682958.2000.tb00770.x.

Caputo, A. (2012). Integrative agreements in multilateral negotiations: The case of Fiat and Chrysler. International Journal of Business and Social Sciences, 3(12), 167-180.

Caputo, A. (2013). A literature review of cognitive biases in negotiation processes. International Journal of Conflict Management, 24(4), 274-398. https://doi.org/10.1108/IJCMA-08-2012-0064.

Caputo, A. (2016). Overcoming judgmental biases in negotiations: A scenario-based survey analysis on third party direct intervention. Journal of Business Research, 69(10), 4304-4312. https://doi.org/http://dx.doi.org/10.1016/j.jbusres.2016.04.004.

Caputo, A. (2019). Strategic corporate negotiations: A framework for Win-Win agreements. London, UK: Palgrave Pivot.

Caputo, A., Ayoko, O. B., \& Amoo, N. (2018). The moderating role of cultural intelligence in the relationship between cultural orientations and conflict management styles. Journal of Business Research, 89, 10-20. https://doi.org/10.1016/j. jbusres.2018.03.042.

Caputo, A., Ayoko, O. B., Amoo, N., \& Menke, C. (2019a). The relationship between cultural values, cultural intelligence and negotiation styles. Journal of Business Research, 99, 23-36. https://doi.org/10.1016/j.jbusres.2019.02.011.

Caputo, A., Marzi, G., Maley, J., \& Silic, M. (2019b). Ten years of conflict management research 2007-2017: An update on themes, concepts and relationships. International Journal of Conflict Management, 30(1), 87-110.

Caputo, A., \& Valenza, G. (2019). Mediation and conciliation in collective labor conflicts in Italy. In M. C. Euwema, F. J. Medina, A. B. Garcia \& E. R. Pender (Eds.), Mediation in collective labor conflicts (pp. 113-127). Cham, Switzerland: Springer.

Cheng, J., Huang, Y., \& Su, Y. (2017). Relationality in negotiations: a systematic review and propositions for future research. International Journal of Conflict Management, 28(3), 295-321.

Clò, C. (2006). Visions of Italy beyond the North/South divide: Regional documentaries and global identities. Annali d'Italianistica, 24, 41-64.

Collins, L. M., \& Lanza, S. T. (2010). Latent class and latent transition analysis: With applications in the social, behavioral, and health sciences. John Wiley \& Sons, Hoboken, New Jersey.

Cominelli, L., \& Lucchiari, C. (2017). Italian Mediators in action: The impact of style and attitude. Conflict Resolution Quarterly, 35(2), 223-242.

Cutcher-Gershenfeld, J., \& Kochan, T. (2015). A behavioral theory advancing negotiation scholarship and practice. Negotiation Journal, 31(4), 319-331.

Der Foo, M., Elfenbein, H. A., Hoon Tan, H., Chuan Aik, V., Maw, D. F., Elfenbein, H. A., ... Chuan Aik, V. (2004). Emotional intelligence and negotiation: The tension between creating and claiming value. International Journal of Conflict Management, 15(4), 411-429. https://doi.org/10.1108/eb022920. 
Dorfman, P., Javidan, M., Hanges, P., Dastmalchian, A., \& House, R. (2012). GLOBE: A twenty year journey into the intriguing world of culture and leadership. Journal of World Business, 47(4), 504-518.

Ebner, N., \& Parlamis, J. (2017). Weaving together theory, research, practice, and teaching: A four-dimensional approach to negotiation and conflict management work. Negotiation and Conflict Management Research, 10(4, SI), 245-251. https:// doi.org/10.1111/ncmr.12107.

Fischhoff, B., \& Beyth, R. (1975). I knew it would happen: Remembered probabilities of once - future things. Organizational Behavior and Human Performance, 13(1), 1-16.

Fisher, R., Ury, W., \& Patton, B. M. (1981). Getting to yes: Negotiating agreement without giving in. Boston: Houghton-Mifflin.

Fosse, S. M., Ogliastri, E., \& Rendon, M. I. (2017). When dignity and honor cultures negotiate: Finding common ground. Negotiation and Conflict Management Research, 10(4), 265-285.

Gelfand, M. J., \& Brett, J. M. (2004). The handbook of negotiation and culture. Stanford University Press.

Gelfand, M. J., Brett, J. M., Gunia, B. C., Imai, L., Huang, T.-J., \& Hsu, B.-F. (2013). Toward a culture-by-context perspective on negotiation: Negotiating teams in the United States and Taiwan. Journal of Applied Psychology, 98(3), 504-513.

Goodman, L. A. (1974). Exploratory latent structure analysis using both identifiable and unidentifiable models. Biometrika, 61(2), 215-231.

Graham, J. L. (2019). A third theory: inventive negotiation. Journal of Business \& Industrial Marketing, 34(4), 703-710.

Graham, J. L., Mintu, A. T., \& Rodgers, W. (1994). Explorations of negotiation behaviors in ten foreign cultures using a model developed in the United States. Management Science, 40(1), 72-95.

Groves, K. S., Feyerherm, A., \& Gu, M. (2015). Examining cultural intelligence and cross-cultural negotiation effectiveness. Journal of Management Education, 39(2), 209-243.

Gunia, B. C., Brett, J. M., \& Gelfand, M. J. (2016). The science of culture and negotiation. Current Opinion in Psychology, 8, 78-83.

Gunkel, M., Schlaegel, C., \& Taras, V. (2016). Cultural values, emotional intelligence, and conflict handling styles: A global study. Journal of World Business, 51(4), 568-585.

Gupta, V., Hanges, P. J., \& Dorfman, P. (2002). Cultural clusters: Methodology and findings. Journal of World Business, 37(1), $11-15$.

Hall, E. T. (1976). Beyond culture. Garden City, NY: Doubleday.

Harinck, F., Shafa, S., Ellemers, N., \& Beersma, B. (2013). The good news about honor culture: The preference for cooperative conflict management in the absence of insults. Negotiation and Conflict Management Research, 6(2), 67-78. https://doi. org/10.1111/ncmr.12007.

Hesse-Biber, S. N. (2010). Mixed methods research: Merging theory with practice. New York: Guilford Press.

Hofstede, G. (2001). Culture's consequences: Comparing values, behaviors, institutions and organizations across nations. Beverly Hills, CA: Sage.

Hofstede, G. (2011). Dimensionalizing cultures: The Hofstede model in context. Online Readings in Psychology and Culture, 2 (1), 1-26.

House, R. J., Hanges, P. J., Javidan, M., Dorfman, P. W., \& Gupta, V. (2004). Culture, leadership, and organizations: The Globe study of 62 societies. Thousand Oaks, CA: Sage Publications.

Imai, L., \& Gelfand, M. J. (2010). The culturally intelligent negotiator: The impact of cultural intelligence (CQ) on negotiation sequences and outcomes. Organizational Behavior and Human Decision Processes, 112(2), 83-98. https://doi.org/10.1016/j. obhdp.2010.02.001.

Kaasa, A., Vadi, M., \& Varblane, U. (2014). Regional cultural differences within European countries: evidence from multicountry surveys. Management International Review, 54(6), 825-852.

Kirkman, B. L., Lowe, K. B., \& Gibson, C. B. (2006). A quarter century of culture's consequences: A review of empirical research incorporating Hofstede's cultural values framework. Journal of International Business Studies, 37(3), 285-320.

Kopelman, S., \& Rosette, A. S. (2008). Cultural variation in response to strategic emotions in negotiations. Group Decision and Negotiation, 17(1), 65-77.

Lax, D. A., \& Sebenius, J. K. (1986). The manager as negotiator: Bargaining for cooperation and competitive gain. New York: Macmillan.

Leung, A. K.-Y., \& Cohen, D. (2011). Within-and between-culture variation: Individual differences and the cultural logics of honor, face, and dignity cultures. Journal of Personality and Social Psychology, 100(3), 507-526.

Lewicki, R. J., Saunders, D., \& Barry, B. (2020). Negotiation (8th ed.). New York: McGraw Hill.

Linzer, D. A., \& Lewis, J. B. (2011). poLCA: An R package for polytomous variable latent class analysis. Journal of Statistical Software, 42(10), 1-29.

Liu, L. A., Chua, C. H., \& Stahl, G. K. (2010). Quality of communication experience: Definition, measurement, and implications for intercultural negotiations. Journal of Applied Psychology, 95(3), 469-488.

Liu, L. A., Friedman, R., Barry, B., Gelfand, M. J., \& Zhang, Z.-X. (2012). The dynamics of consensus building in intracultural and intercultural negotiations. Administrative Science Quarterly, 57(2), 269-304.

Luomala, H. T., Kumar, R., Singh, J. D., \& Jaakkola, M. (2015). When an intercultural business negotiation fails: Comparing the emotions and behavioural tendencies of individualistic and collectivistic negotiators. Group Decision and Negotiation, 24(3), 537-561. 
Ma, Z., Lee, Y., \& Yu, K. (2008). Ten years of conflict management studies: Themes, concepts and relationships. International Journal of Conflict Management, 19(3), 234-248. https://doi.org/10.1108/10444060810875796.

Metcalf, L. E., Bird, A., Shankarmahesh, M., Aycan, Z., Larimo, J., \& Valdelamar, D. D. (2006). Cultural tendencies in negotiation: A comparison of Finland, India, Mexico, Turkey, and the United States. Journal of World Business, 41(4), $382-394$.

Morris, M. W., \& Gelfand, M. J. (2004). Cultural differences and cognitive dynamics: Expanding the cognitive perspective on negotiation. In M. J. Gelfand \& J. Brett (Eds.), The handbook of negotiation and culture (pp. 45-70). Stanford, CA: Stanford University Press.

Nielsen, B. B., Welch, C., Chidlow, A., Miller, S. R., Aguzzoli, R., Gardner, E., ... \& Pegoraro, D. (2020). Fifty years of methodological trends in JIBS: Why future IB research needs more triangulation. Journal of International Business Studies, 51(9), 1478-1499.

Ogliastri, E., McMillen, C., Arias, M. E., Dávila, C., Dorfman, P., Fimmen, C., .. Martínez, S. (1999). Cultura y liderazgo organizacional en 10 países de América Latina. El estudio Globe. Academia. Revista Latinoamericana de Administración (22), 29-57.

Ogliastri, E., \& Quintanilla, C. (2012). Developing a theory of negotiations in Latin America. A study of the integrative and distributive theory of negotiations. XLVII CLADEA Conference. Lima.

Ogliastri, E., \& Quintanilla, C. (2016). Building cross-cultural negotiation prototypes in Latin American contexts from foreign executives' perceptions. Journal of Business Research, 69(2), 452-458.

Ogliastri, E., Rendón, M. I., \& Fosse, S. M. (2017). Negociación a la Francesa: un enfoque cualitativo. Cuadernos de Administración, 30(54), 91-124.

Patton, B. (2015). Managing the value and danger of dualities. Negotiation Journal, 31, 349.

Posthuma, R. A. (2012). Conflict management and emotions. International Journal of Conflict Management, 23(1), 4-5. https://doi.org/10.1108/10444061211210797.

Pruitt, D. G. (1981). Negotiation behavior. New York: Academic Press.

Pruitt, D. G., \& Rubin, J. Z. (1986). Social conflict: Escalation, impasse, and resolution. Reading, MA: Addison-Wesley.

Ramirez Marin, J., Olekalns, M., \& Adair, W. (2019). Normatively speaking: Do cultural norms influence negotiation, conflict management, and communication? Negotiation and Conflict Management Research, 12(2), 146-160.

Salacuse, J. W. (1999). Intercultural negotiation in international business. Group Decision and Negotiation, 8(3), 217-236. Retrieved from https:/www.scopus.com/inward/record.uri?eid=2-s2.0-0033439320\&partnerID=40\&md5= b82523b752a7dfd69b966b1b88ec12dd.

Schlegel, K., Mehu, M., van Peer, J. M., \& Scherer, K. R. (2018). Sense and sensibility: The role of cognitive and emotional intelligence in negotiation. Journal of Research in Personality, 74, 6-15.

Sharma, S., Bottom, W. P., \& Elfenbein, H. A. (2013). On the role of personality, cognitive ability, and emotional intelligence in predicting negotiation outcomes: A meta-analysis. Organizational Psychology Review, 3(4), 293-336.

Usunier, J.-C. (2018). Intercultural business negotiations: Deal-making or relationship building. Routledge.

Vieregge, M., \& Quick, S. (2011). Cross-cultural negotiations revisited. Cross Cultural Management, 18(3), 313-326. https:// doi.org/10.1108/13527601111152842.

Walton, R. E., \& McKersie, R. B. (1965). A behavioral theory of labor negotiations. Beverly Hills, CA: Sage Publications.

Wong, S. S. (2020). Mapping the Repertoire of Emotions and Their Communicative Functions in Face-to-face Diplomacy. International Studies Review, 22(1), 77-97.

Yao, J., Ramirez-Marin, J., Brett, J., Aslani, S., \& Semnani-Azad, Z. (2017). A measurement model for dignity, face, and honor cultural norms. Management and Organization Review, 13(4), 713.

Yao, J., Zhang, Z., \& Brett, J. M. (2017). Understanding trust development in negotiations: An interdependent approach. Journal of Organizational Behavior, 38(5), 712-729.

Zhang, Q., Oetzel, J. G., Ting-Toomey, S., \& Zhang, J. (2019). Making up or getting even? The effects of face concerns, selfconstrual, and apology on forgiveness, reconciliation, and revenge in the United States and China. Communication Research, 46(4), 503-524. 
Appendix 1: Hofstede's cultural dimensions: Italy versus United States

\begin{tabular}{|c|c|c|c|c|}
\hline \multirow[b]{2}{*}{ Hofstede's cultural dimensions } & \multicolumn{2}{|c|}{ Italy } & \multicolumn{2}{|c|}{ United States } \\
\hline & Index ${ }^{a}$ & $\operatorname{Rank}(/ 63)^{\mathrm{b}, \mathrm{c}}$ & Index & Rank (/63) \\
\hline Power distance & 50 & 41 & 40 & 48 \\
\hline Individualism & 76 & 8 & 91 & 1 \\
\hline Masculinity & 70 & 7 & 62 & 16 \\
\hline Uncertainty avoidance & 75 & 28 & 46 & 52 \\
\hline Long-term orientation & 61 & 20 & 26 & 52 \\
\hline
\end{tabular}

${ }^{a} \mathrm{~A}$ higher value of the index indicates that the characteristic under study is more prominent.

'Ranking positions are calculated from the 'dimension data matrix' (https://geerthofstede.com/research-and-vsm/dimension-data-matrix/), considering only the 63 countries for which all five indices are available (power distance, uncertainty avoidance, individualism vs. collectivism, masculinity vs. femininity, and long- vs. short-term orientation).

${ }^{C}$ The ranking goes from 1 to 63 , with 1 indicating the stronger characterization of the cultural trait under study (higher index) and 63 indicating the weaker characterization of the cultural trait (lower index).

\section{Appendix 2: Intercultural negotiation: Questions about 20 topics}

(1) Negotiation culture: Summing up: how do they negotiate?

(2) Perception of the other party: Do they conceive the counterpart as a friend, a colleague, a rival, or neutrally impersonal?

(3) Time perspective: Are they long-term or short-term oriented?

(4) Trust base: Is trust based on the person, on the legal system and the written contract, or on previous experience?

(5) Risk taking: Do they take risks of not delivering commitments?

(6) Who are the negotiators: What criteria do they use to select negotiators?

(7) Decision making: How do they decide and who makes decisions?

(8) Formality: Are they informal/formal, do they follow a protocol, how close is interpersonal treatment?

(9) Informal negotiations: Do they use out-of-the-office negotiations?

(10) Prenegotiations (and negotiation preparation): Do they have previous meetings? Do they come prepared?

(11) Opening: Do they open with extreme offers, use objective criteria to justify offers, haggling?

(12) Arguments: Do they use persuasion, emotionally moving language, hard data, threats, rational debate?

(13) Emotionality: Do they induce a rational or emotional process, expressive or instrumental use of feelings?

(14) Power tactics: Threats, intimidation, fake lack of interest, aggressiveness, confrontation?

(15) Discussion level: Do they discuss details or generalities?

(16) Time during negotiation: Are they punctual, polychronic, slow, agenda focused?

(17) Type of agreement: Oral, in writing, legal, official agreements?

(18) Commitment and fulfillment: Are agreements binding?

(19) Perception flexibility: Are they rigid or flexible about changes?

(20) Ways of expression: Interpersonally friendly, courteous, confrontational, diplomatic, imposing, evasive, neutral? 


\section{Appendix 3: Sample of the codebook}

(1) Emotionality: Do they induce a rational or emotional process, expressive or instrumental use of feelings?

Questions: How much room is left for expressing emotions during the negotiation, or is it a neutral and objective process? Is there room for personal expression needs or is it an instrumental technique meant to influence the other party? Are hostility and affection displayed by only one of the parties or by neither of the two?

Codebook:

Do they express emotions in negotiations? Yes (emotional) No (neutral, objective, rational, formality)

_ Not sure, no information, I don't know

Expressive nature of feelings expressed in negotiations?

Yes (ventilating feelings is acceptable for them, expressive culture)

No (it is not accepted, not considered professional or mature)

Not sure, no information, I don't know

Instrumental nature of feelings expressed in negotiations?

Yes (feelings are a tool to impress, a negotiation tactic, impact oriented)

No (they are not used, or considered hypocrisy and bad manners)

Not sure, no information, I don't know

Do they express hostility as a normal feeling during negotiations?

Yes (it is considered normal to express some hostility)

No (it is not acceptable)

Not sure, no information, I don't know

Do they express affection during negotiations?

Yes (it is acceptable and normal)

No (it is not common, not customary)

Not sure, no information, I don't know

\section{Appendix 4: Formal international negotiation questionnaire}

(1) Specifically, think of one concrete formal negotiation in which you participated and which involved people or entities from two countries.

(2) What were the previous issues (interests) leading up to this negotiation? What would have happened to each party if no agreement was reached; what were their alternatives?

(3) How did you and they prepare for this negotiation? What were the prenegotiations? How did they approach you?

(4) How did they decide who was going to negotiate, what would be on the agenda, where the negotiation would take place?

(5) How did the negotiation begin? (Was it a haggling/bargaining process with an excessive opening demand?) Who opened the negotiation? How did each of the parties go about their openings? Were objective criteria sought or established or was it a mere bargaining of positions?

(6) What were the main incidents in the transaction? How did you get the most important points? 
(7) How was the closure of the deal? Was it a satisfactory to both parties?

(8) What drew your attention the most in this experience? What did you like most? What did you like least? Do you think people from the other country are similar or dissimilar to you? What are they like?

(9) Do you think this was a typical experience? Have you had experiences with people from the same country or culture that differ much from this one?

(10) What advice would you give someone going to this country to negotiate?

(11) In brief, how do people from this country usually negotiate? What is the difference found in the negotiation you just recounted?

(12) If you had to do this negotiation again, would you change your behavior? What would you do in a different way and why? 